Atmos. Chem. Phys., 20, 14969-14982, 2020

https://doi.org/10.5194/acp-20-14969-2020

(C) Author(s) 2020. This work is distributed under

the Creative Commons Attribution 4.0 License.

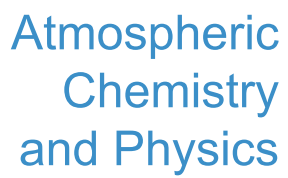

(c) (P)

\title{
Is there a direct solar proton impact on lower-stratospheric ozone?
}

\author{
Jia Jia $^{1}$, Antti Kero ${ }^{1}$, Niilo Kalakoski ${ }^{2}$, Monika E. Szelag ${ }^{2, \mathbf{i}}$, and Pekka T. Verronen ${ }^{1,2}$ \\ ${ }^{1}$ Sodankylä Geophysical Observatory, University of Oulu, Sodankylä, Finland \\ ${ }^{2}$ Space and Earth Observation Centre, Finnish Meteorological Institute, Helsinki, Finland \\ i previously published under the name M. E. Andersson
}

Correspondence: Jia Jia (jia.jia@oulu.fi)

Received: 23 March 2020 - Discussion started: 12 May 2020

Revised: 9 September 2020 - Accepted: 8 October 2020 - Published: 4 December 2020

\begin{abstract}
We investigate Arctic polar atmospheric ozone responses to solar proton events (SPEs) using MLS (Microwave Limb Sounder) satellite measurements (2004-now) and WACCM-D (Whole Atmosphere Community Climate Model) simulations (1989-2012). Special focus is on lowerstratospheric $(10-30 \mathrm{~km})$ ozone depletion that has been proposed earlier based on superposed epoch analysis (SEA) of ozonesonde anomalies (up to $10 \%$ ozone decrease at $\sim 20 \mathrm{~km}$ ). SEA of the satellite dataset provides no solid evidence of any average SPE impact on the lower-stratospheric ozone, although at the mesospheric altitudes a statistically significant ozone depletion is present. In the individual case studies, we find only one potential case (January 2005) in which the lower-stratospheric ozone level was significantly decreased after the SPE onset (in both model simulation and MLS observation data). However, similar decreases could not be identified in other SPEs of similar or larger magnitude. Due to the input proton energy threshold of $>300 \mathrm{MeV}$, the WACCM-D model can only detect direct proton effects above $25 \mathrm{~km}$, and simulation results before the Aura MLS era indicate no significant effect on the lower-stratospheric ozone. However, we find a very good overall consistency between WACCM-D simulations and MLS observations of SPE-driven ozone anomalies both on average and for the individual cases including January 2005.
\end{abstract}

\section{Introduction}

In the near-Earth space, solar wind charged particles are guided by the Earth's magnetic field and are able to precipitate into the middle and upper atmosphere in the polar re- gions. Such a kind of precipitation creates the spectacular aurora but also produces considerable amounts of $\mathrm{HO}_{x}(\mathrm{H}, \mathrm{OH}$, $\left.\mathrm{HO}_{2}\right)$ and $\mathrm{NO}_{x}\left(\mathrm{~N}, \mathrm{NO}, \mathrm{NO}_{2}\right)$ through ion-neutral chemistry (e.g., Verronen and Lehmann, 2013). $\mathrm{HO}_{x}$ and $\mathrm{NO}_{x}$ increases lead to ozone loss through catalytic reactions in the mesosphere and upper stratosphere, respectively (Sinnhuber et al., 2012). Moreover, in polar winter, $\mathrm{NO}_{x}$ has a long chemical lifetime due to limited photodissociation by solar radiation. $\mathrm{NO}_{x}$ produced by energetic particle precipitation (EPP) in the mesosphere to lower thermosphere is transported down to the stratosphere by the Brewer-Dobson circulation inside the polar vortex (Funke et al., 2014), causing depletion of upper-stratospheric ozone (Damiani et al., 2016). A number of studies have confirmed EPP's remarkable role in ozone depletion directly during large EPP events (e.g., Funke et al., 2011) and indirectly due to descending $\mathrm{NO}_{x}$ (e.g., Randall et al., 2007). Thus, many advanced chemistryclimate models are now including EPP forcing, in order to correctly represent the ozone distribution in the polar stratosphere and mesosphere (Matthes et al., 2017; Stone et al., 2018).

Solar proton events (SPEs) are one of the main types of EPP. During SPE, particles (mainly protons) with energies from tens to hundreds of megaelectronvolt $(\mathrm{MeV})$ precipitate into the atmosphere at geomagnetic latitudes larger than $60^{\circ}$ for days. Such high-energy particles mainly affect the atmosphere at altitudes of $35-90 \mathrm{~km}$, providing direct ionization forcing on the polar middle atmosphere. Large SPEs have been studied since the 1960s up to today using satellite observations and model simulation. In addition to tens of percent of ozone loss observed at altitudes above $35 \mathrm{~km}$ (Jackman et al., 2001; Seppälä et al., 2004; Verronen et al., 2006), a strong 
SPE can reduce total ozone by $1 \%-3 \%$ for months after the event (Jackman and Fleming, 2008; Jackman et al., 2014).

Recently, Denton et al. (2018a, b) presented statistical studies of average ozone changes from 191 SPEs between 1989 and 2016 using ozonesonde measurements. Superposed epoch analysis of ozone anomalies at polar stations (Sodankylä, Ny-Ålesund and Lerwick) indicated that SPEs occurring during winter are causing ozone decrease by $5 \%-$ $10 \%$, on average, at $20 \mathrm{~km}$ altitude. This effect is not produced in the current models because SPE-induced ionization rates are insignificant at this altitude even during the largest events with high proton energies from 300 to $20000 \mathrm{MeV}$ (Jackman et al., 2011). Denton et al. (2018a, b) included also a large number of very small SPEs in their analysis. Such ozone decreases have not been observed in the case studies of very extreme (particles with energies $>10 \mathrm{MeV}$ are greater than $10000 \mathrm{pfu}$, particle flux units) SPEs, e.g., the 2003 "Halloween" event, from either simulation or satellite observation (Funke et al., 2011, and references therein). Recently, statistical analysis based on simulations has found no evidence of such low-altitude ozone impact (Kalakoski et al., 2020). Moreover, from the chemical aspect, we also rather expect ozone increase in the lower stratosphere due to the enhanced $\mathrm{NO}_{x}$ interfering with chlorine-driven catalytic ozone loss (Jackman et al., 2008).

Here we investigate the proposed SPE-induced direct depletion on lower-stratospheric (10-30 km) ozone using ozone data from the Microwave Limb Sounder (MLS) instrument aboard the Aura satellite and the Whole Atmosphere Community Climate Model (WACCM-D) simulations. We proceed to evaluate ozone changes at altitudes of $10-70 \mathrm{~km}$ caused by SPEs both statistically (superposed epoch analysis) and individually (case by case). The MLS ozone data, WACCM-D atmospheric simulation and SPE datasets are presented in Sect. 2. In order to cross-check ozone depletion at $20 \mathrm{~km}$ reported based on the ozonesonde data, statistical ozone responses from MLS satellite measurements are firstly provided in Sect. 3. Following that, MLS and WACCM-D ozone changes after individual SPEs are given in Sect. 4. Finally, we summarize our results and conclusions in Sect. 5.

\section{Datasets}

\section{$2.1 \quad \mathrm{O}_{3}$ profile measurements by MLS}

MLS onboard the Earth Observing System (EOS) Aura satellite measures ozone emission at $240 \mathrm{GHz}$, providing ozone volume mixing ratios at 55 pressure levels since 15 July 2004 (Waters et al., 2006). Vertical profiles are retrieved from the MLS observations every $165 \mathrm{~km}$ along the polar orbit at altitudes between 8 and $90 \mathrm{~km}$, with a vertical resolution of $\sim 3.2 \mathrm{~km}$. In this work, we use version 4.2 ozone data measured at $261-0.02 \mathrm{hPa}(\sim 10-70 \mathrm{~km})$ to calculate the daily averaged ozone density profile at northern high latitudes (60- $\left.90^{\circ} \mathrm{N}\right)$. Readers who are interested in the MLS data quality are referred to Livesey et al. (2018).

\section{$2.2 \mathrm{O}_{3}$ from WACCM-D simulations}

WACCM is a global circulation model, including fully coupled dynamics and chemistry. Here, we use version 4 of WACCM with resolution of $1.9^{\circ}$ latitude by $2.5^{\circ}$ longitude, with 88 vertical levels reaching from surface to $6 \times 10^{-6} \mathrm{hPa}$ $(\approx 140 \mathrm{~km})$. Overview of the model and the description of climate and variability in long-term simulation was presented by Marsh et al. (2013), with details of model physics in MLT (mesosphere to lower thermosphere region) and the response of the model to radiative and geomagnetic forcing during solar maximum and minimum described by Marsh et al. (2007). The simulation results presented here are from WACCM-D, a variant of WACCM with a more detailed set of lower ionospheric chemical reactions, aiming at better reproduction of observed effects of EPP on MLT neutral composition (Verronen et al., 2016; Andersson et al., 2016).

We use SD-WACCM-D specified dynamics configuration, with Modern-Era Retrospective analysis for Research and Applications (MERRA) (Rienecker et al., 2011) meteorological fields to force dynamics at every time step up to about $50 \mathrm{~km}$. Simulation covers years 1989-2012 and uses forcings from auroral electrons $(E<10 \mathrm{keV})$, solar protons $(E<300 \mathrm{MeV})$ and galactic cosmic rays for energetic particle precipitation. The SPE ionization rates are based on proton flux measurements from the Geostationary Operational Environmental Satellite (GOES) (see e.g., Jackman et al., 2011 , for the calculation method). The WACCM-D SPE effects on neutral species are compared to satellite observations in Andersson et al. (2016). Note that WACCM-D has not been validated below $20 \mathrm{~km}$. Nevertheless, in Andersson et al. (2016) the $\mathrm{HNO}_{3}$ response above $15 \mathrm{~km}$ to single SPE onset was reasonable compared to MLS data. We also stress that protons with energies over $300 \mathrm{MeV}$ are not included in the simulation. The $300 \mathrm{MeV}$ protons mostly affect the atmosphere at around $25 \mathrm{~km}$ (Turunen et al., 2009). As $300 \mathrm{MeV}$ is the upper limit of the proton energies considered in our model simulation, the WACCM-D simulation presented here can therefore only investigate the impact of direct proton forcing at altitudes above $25 \mathrm{~km}$. For more details of the simulation setup, see Kalakoski et al. (2020).

\subsection{Solar proton events}

The data of solar proton events (SPEs) used in this study are based on NOAA GOES proton flux observations. Figure 1 presents 261 SPEs recorded from 1975 to date, including their onset time, fluxes detected in space, approximated time of duration and average ionization rates to the atmosphere at two altitudes. Here, the onset of a SPE is defined as the time when $5 \mathrm{~min}$ average proton fluxes with energies $>10 \mathrm{MeV}$ are greater than 10 particle flux units $(1 \mathrm{pfu}=1$ 

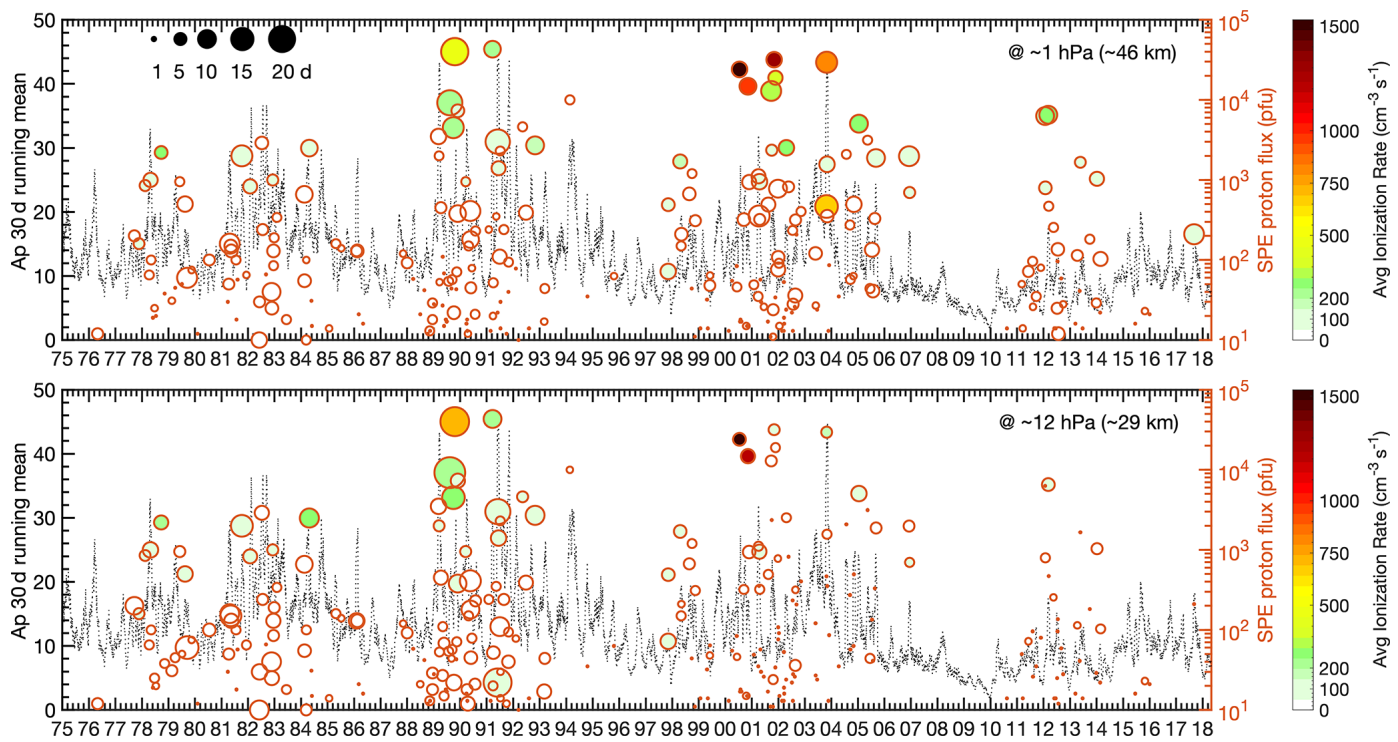

Figure 1. Onset time of SPEs and their proton fluxes since 1975. The filled colors are the average ionization rates during each SPE at $\sim 1 \mathrm{hPa}$ (upper panel) and $\sim 12 \mathrm{hPa}$ (lower panel), while the size of the markers represents the approximate duration of the SPEs obtained from the daily mean ionization rate at the two altitudes. The black dotted line in the background is the $30 \mathrm{~d}$ mean of the daily geomagnetic activity Ap-index.

particle $/ \mathrm{cm}^{2} / \mathrm{s} / \mathrm{sr}$ ) at the geosynchronous orbit. For the estimation of SPE duration and its impact on the atmosphere, we use the daily average ion pair production rates at $\sim 1 \mathrm{hPa}$ ( $\sim 46 \mathrm{~km}$, upper panel of Fig. 1$)$ and $\sim 12 \mathrm{hPa}(\sim 29 \mathrm{~km}$, lower panel of Fig. 1). These ionization rates are calculated from GOES proton flux observations using the energy deposition methodology described in, for example, Jackman et al. (2011). The SPE durations presented here were calculated as the period when the ionization rates at $\sim 1$ and $12 \mathrm{hPa}$ are larger than 2 ion $\mathrm{pair} / \mathrm{cm}^{3} / \mathrm{s}$ before the next event starts. The average ionization rates in Fig. 1 were then derived by averaging the ionization rates at 1 and $12 \mathrm{hPa}$ during this period. Our study used 49 events that occurred after the launch of Aura MLS (July 2004-now) and 177 events that occurred in the complete WACCM-D simulation period (January 1989December 2012) to evaluate the ozone changes following SPEs. It is clearly demonstrated in Fig. 1 that these SPEs are more frequent near solar maximum years. A majority of the events are with flux less than $400 \mathrm{pfu}$, and their impacts to the atmosphere below $1 \mathrm{hPa}$ are small. It is worth mentioning that although these SPEs seem to have no preference in occurring season, their seasonal distribution varies by months and should be considered during the interpretation (Fig. A1 in the Appendix).

\subsection{Statistical $\mathrm{O}_{3}$ response from MLS}

Similar to the method used by Denton et al. (2018b), we applied a superposed epoch analysis to the MLS daily ozone anomalies. The superposed epoch analysis, also referred to as composite analysis in geophysics, is used to acquire vari- ation of a time series before and after an event or a chain of certain kinds of events. The point of time when the event begins is the epoch time. In this case, the epoch times are the onset times of individual SPEs during the MLS operating period. All available ozone data were binned as a function of epoch time and altitude, with temporal resolution of $1 \mathrm{~d}$. The pre- and post-epoch spans used here are 30 and $60 \mathrm{~d}$, respectively. For the selected sets of SPEs, all the binned ozone datasets were averaged to represent the effect of the SPEs. This method excludes natural ozone variations that are larger than the span scale. Since SPE-driven effects are expected to take place on daily to monthly timescales, variations caused by, for example, QBO (quasi-biennial oscillation) can be excluded. However, seasonal variations must be excluded before using superposed epochs. Thus, the daily profile climatology calculated from the ozone data was subtracted from the daily ozone data. Different from Denton et al. (2018a, b), to make sure SPEs are "isolated" from the previous events, events that happened within $10 \mathrm{~d}$ of the previous SPE were excluded.

In order to test the statistical significance of the obtained results, a Monte Carlo test was implemented. Instead of using SPE onset as epoch times, the analysis was rerun using 2000 random sets of epoch times. SPE-epoch averaged variations larger than $95 \%$ of the 2000 randomized results are considered significant and robust (reported as $>95 \%$ confidence), suggesting that these extracted signatures are likely not random but related to SPE or driven by some other external forcing. 

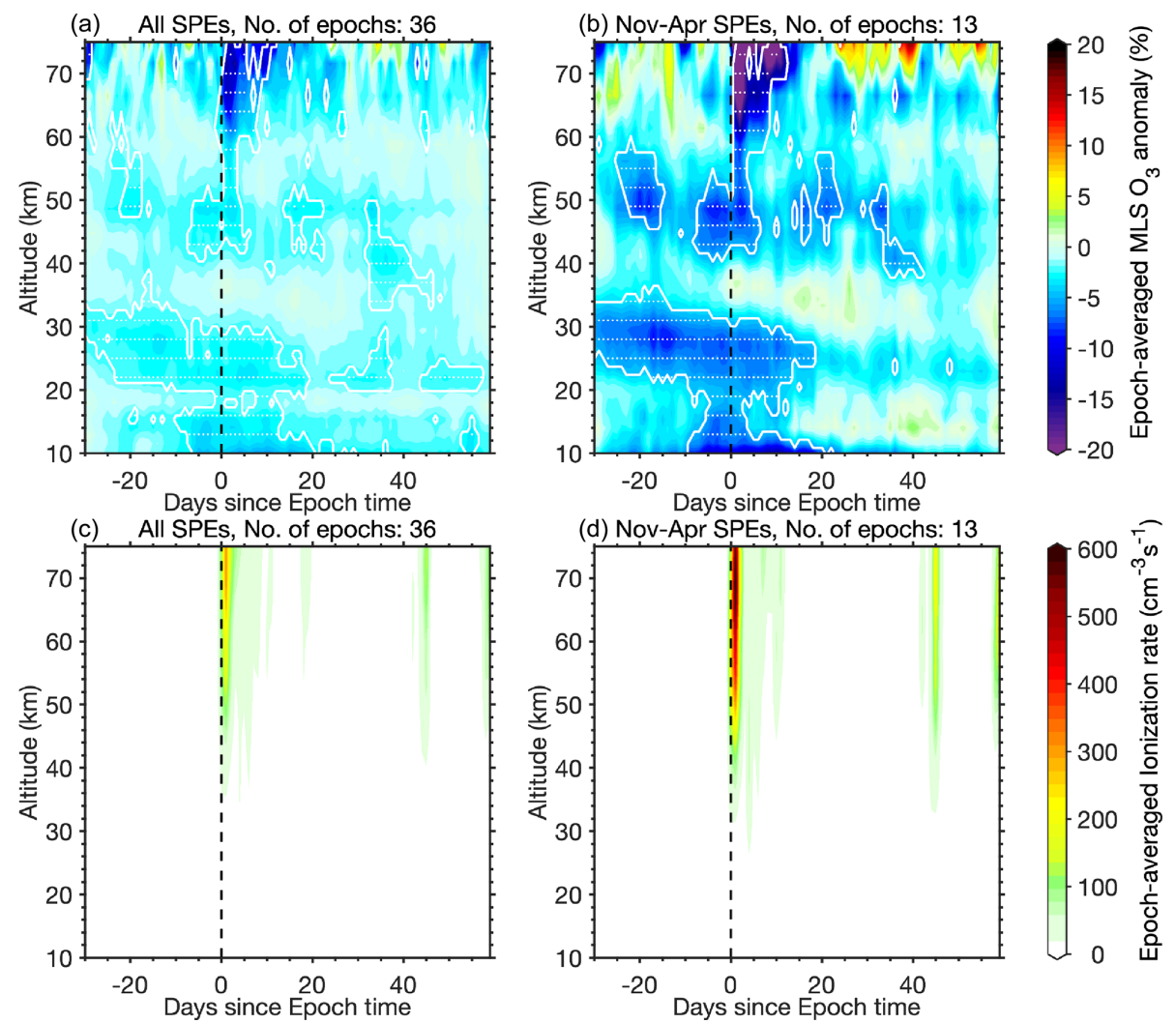

Figure 2. Epoch-averaged MLS ozone anomalies (relative in \%) (a, b) and the corresponding daily ionization rates (c, d) in the northern polar region $\left(60-90^{\circ} \mathrm{N}\right)$ along with geopotential altitude for a total of 35 isolated SPE epochs (a, c) and 13 isolated winter SPE epochs (b, d). The black dashed line represents the epoch time, i.e., onset of SPEs. The white thick line area corresponds to the epoch-averaged anomalies with $>95 \%$ confidence after the Monte Carlo test.

Figure 2 shows the superposed epoch of MLS northern polar ozone anomalies and the corresponding daily ionization rates for all isolated SPEs (35 out of 49 events, Fig. 2a and c) and for the ones occurring in winter (November-April) (13 out of 19 events, Fig. $2 b$ and d) within the instrument's operational period. Robust averaged anomalies ( $>95 \%$ confidence) are presented within the white thick lines. Spatial distribution of statistically robust anomalies is similar in allSPE epochs and winter-SPE epochs. The depletion is more pronounced for winter epochs. This, of course, could be a statistical effect due to the much lower number of events used in the study but is also expected due to two facts: (1) ozone recovery is slower due to less production from $\mathrm{O}_{2}$ photodissociation and (2) the largest SPEs with a flux $>1000$ pfu that cause more ozone depletion to happen to occur in NH winter. Among all the SPEs during MLS measurement period, $\sim 3 / 4$ of large SPEs are in NH wintertime (see Fig. A1). In both upper panels, closely following the SPE onset, very pronounced ozone depletion appears above $50 \mathrm{~km}$ for over $5 \mathrm{~d}$. This is the direct ozone loss caused by the SPE-induced $\mathrm{HO}_{x}$ enhancement. The number of extreme SPEs is relatively small, which explains the absence of the long-lasting ozone depletion that would be expected between 40 and $50 \mathrm{~km}$ from enhanced amounts of $\mathrm{NO}_{x}$. While the upper-stratospheric ozone depletion signature is not seen in the statistical average, a $5 \%-10 \%$ decrease of ozone is present below $30 \mathrm{~km}$, including ozone loss around $20 \mathrm{~km}$ similar to that reported by Denton et al. (2018a, b). However, since this variation starts already several days before the epoch, we cannot exclude the possibility that the whole robust variation in the stratosphere is more related to other phenomena in the northern polar cap, e.g., to changes in the strength of polar vortex or related chemical effects. We will discuss this in more detail in Sect. 4.

A superposed epoch analysis of WACCM-D ozone anomalies from SPEs during 1989-2012 has been reported by Kalakoski et al. (2020); thus, we will not repeat it here. In their results, the epoch-averaged WACCM-D ozone anomalies showed the same robust depletion at above $50 \mathrm{~km}$. Since their analysis included also the very large SPEs that occurred in 1989-2004 (see Fig. 1 in this study or the list of 15 largest SPEs in Table 1 in Jackman et al., 2008), long-term ozone depletion in the upper stratosphere was clearly detected as well. However, there was no robust ozone loss below $30 \mathrm{~km}$ found in the WACCM-D simulations. 

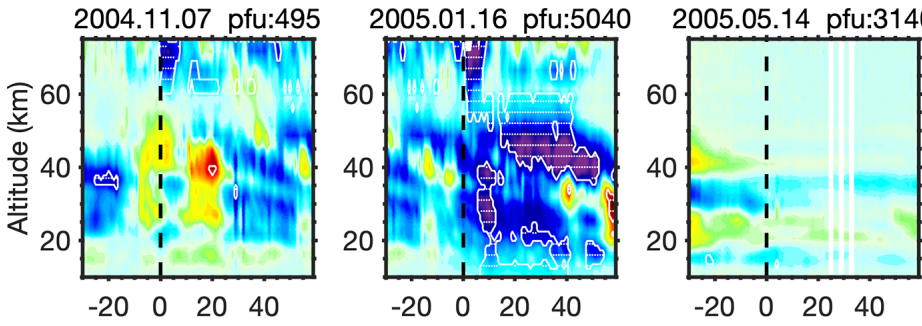

2005.09.08 pfu:1880
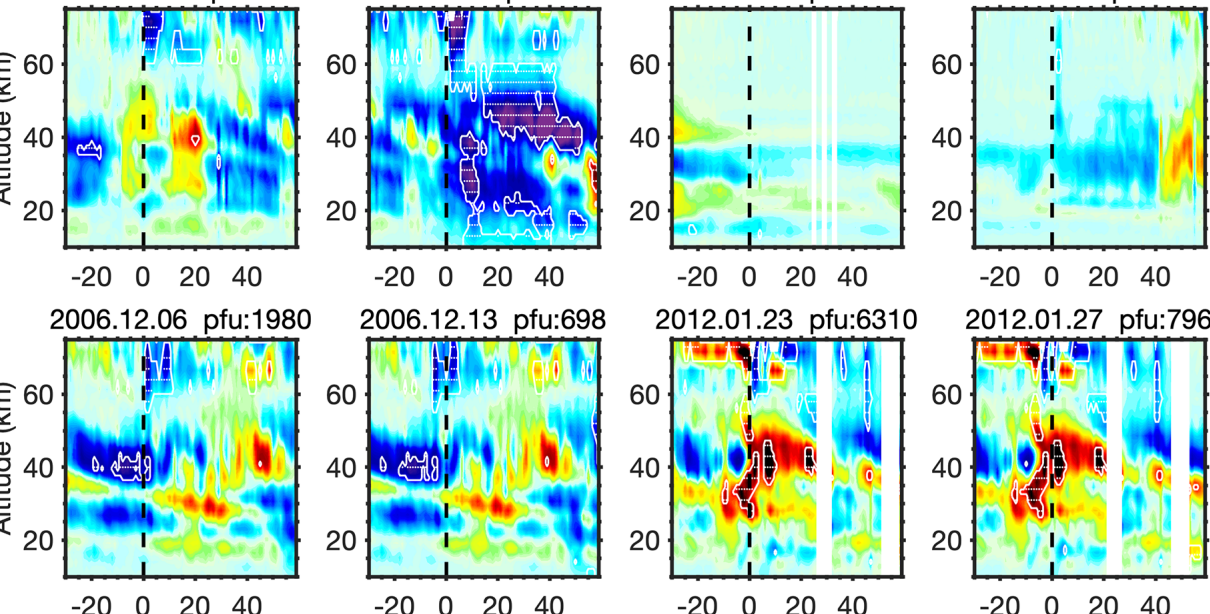

1
0.8
0.6
0.4
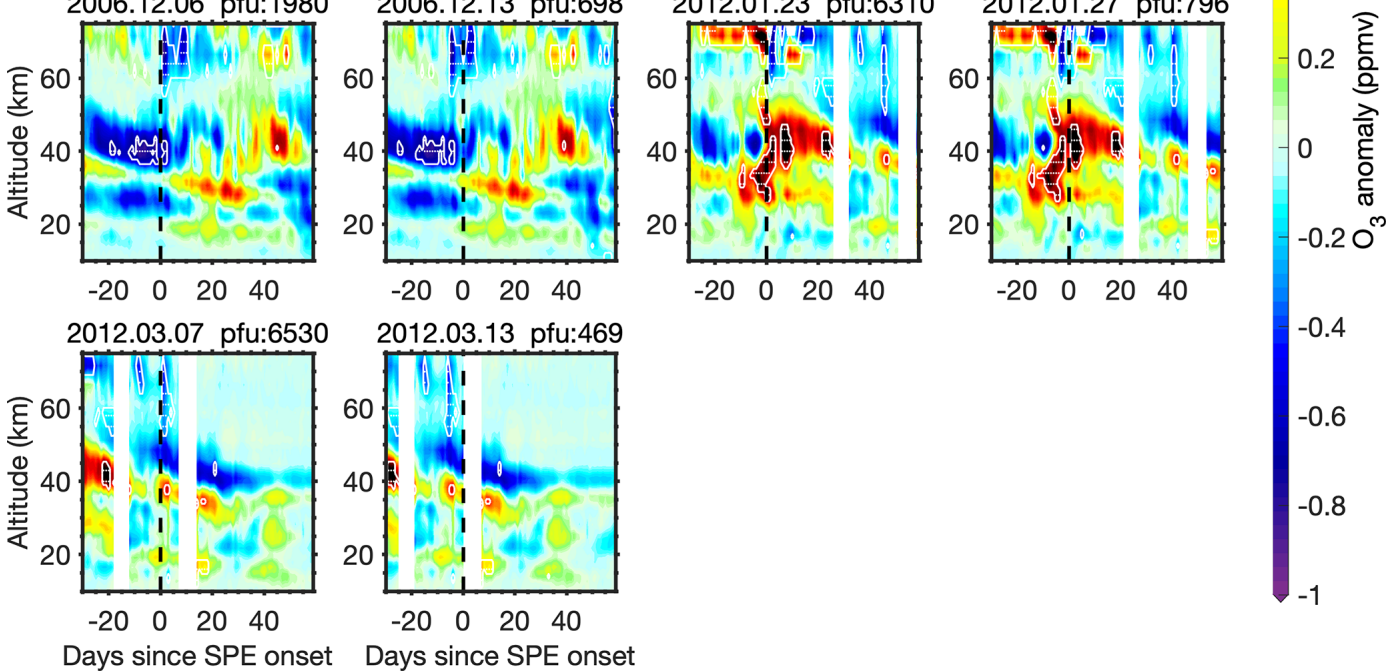

Figure 3. MLS ozone anomalies (in ppmv) along with altitude at $30 \mathrm{~d}$ before and $60 \mathrm{~d}$ after individual large SPEs (proton fluxes $>400$ pfu) in July 2004-December 2012. The white thick line area demonstrates ozone anomalies with > $95 \%$ confidence after the Monte Carlo test.
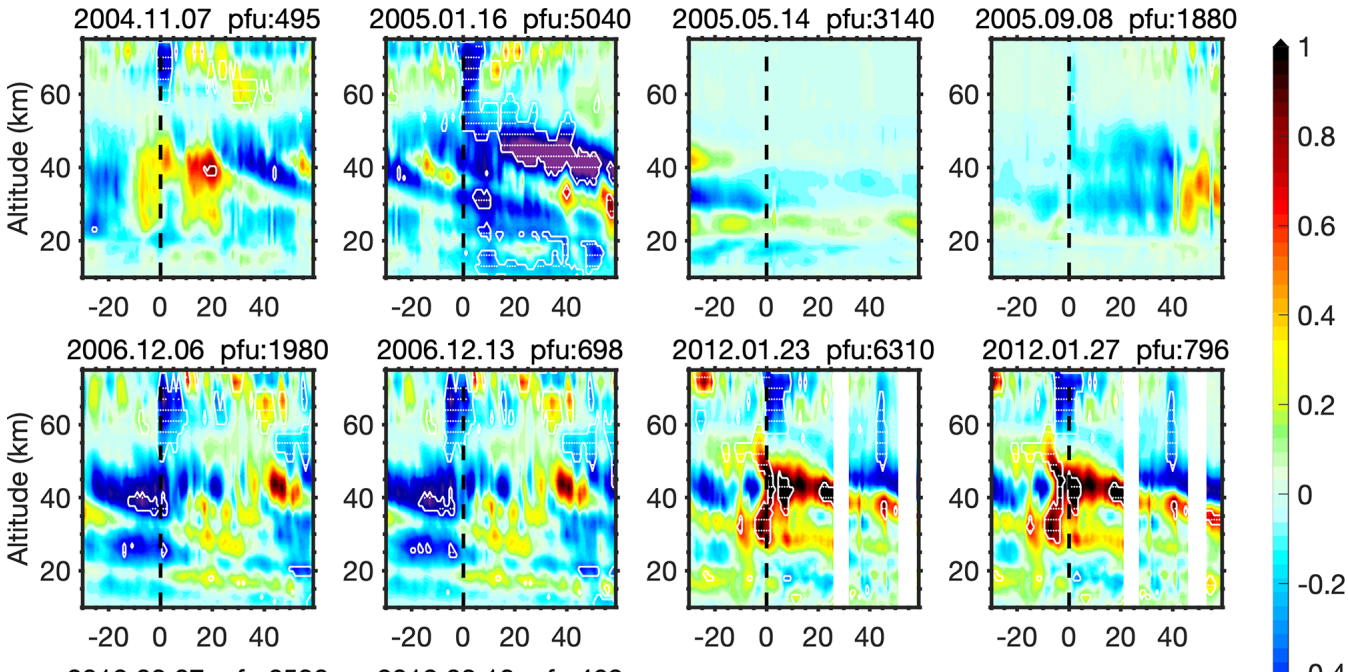

0.4
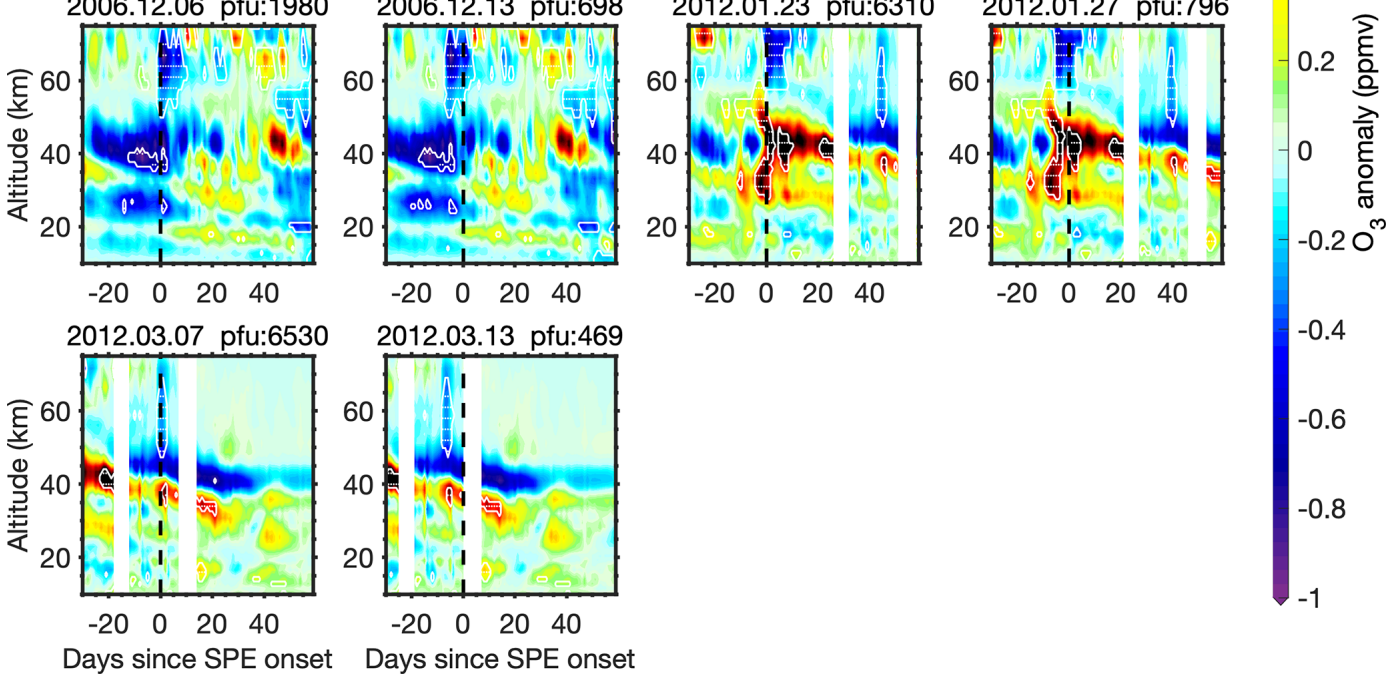

Figure 4. Same as Fig. 3 but for ozone anomalies from WACCM-D simulation at MLS measurement time and location. 


\section{$2.5 \mathrm{O}_{3}$ response to individual SPES}

Considering the limited number of SPE events during MLS era and the high variability of stratospheric ozone influenced by, for example, sudden stratospheric warmings (SSWs) or heterogeneous chemistry on polar stratospheric cloud (PSC) surfaces, particularly during winter, in this section we analyze ozone responses to individual SPEs.

Similar to the analysis presented in Sect. 3, ozone anomalies presented here were calculated by subtracting daily climatology from daily averaged ozone data from MLS and WACCM-D. For Figs. 3 and 4, to make the results from MLS and WACCM-D simulation comparable, WACCM-D daily ozone was calculated using simulation profiles at MLS observation time and location. The climatology from MLS and WACCM-D were derived from their overlapping time period to guarantee a comparable background. For Figs. 6, A2 and A3, the subtracted daily mean climatology from MLS and WACCM-D were derived from the MLS data period and the WACCM-D simulation period, respectively. Then, instead of applying superposed epoch analysis on multiple SPEs, ozone anomalies are presented $30 \mathrm{~d}$ before and $60 \mathrm{~d}$ after onset of individual SPE. For estimating the statistical significance of the ozone anomalies found in the individual SPEs, we applied a similar Monte Carlo approach as in the case of SEA, i.e., the variance of 6000 random "onset" times was used as a measure for a significant anomaly. It is worth noting, however, that this method recognizes all "statistically significant" anomalies larger than the random background variation, whether the anomaly is due to SPE or, for instance, due to exceptional dynamical and chemical anomalies, which have a similar occurrence probability as SPEs.

Anomalies following all individual SPEs can be found in Figs. A2 and A3. In general, SPEs with proton fluxes $<400$ pfu do not cause visible daily ozone depletion in the mesosphere (below $75 \mathrm{~km}$ ) nor in other altitudes. Ozone changes following individual SPEs are more pronounced during winter. Figures 3 and 4 demonstrate MLS and WACCM-D ozone variations following SPEs with proton fluxes $>400$ pfu in July 2004 to the end of 2012. Both the ozone variations and the robust signatures from these two different datasets are very consistent. After 2004, three large winter SPEs, i.e., January 2005, September 2005 and March 2012, produced clear upper-stratospheric ozone loss. Ozone depletion is most pronounced following the January 2005 event. For this event, we also observe a robust lowerstratospheric ozone loss from MLS following SPE for the first time: ozone is depleted by $\sim 1 \mathrm{ppmv}(\sim 15 \%)$ at 20 $35 \mathrm{~km}$ and by $\sim 0.15 \mathrm{ppmv}$ (>20\%) below $15 \mathrm{~km} 5 \mathrm{~d}$ after SPE onset.

Overall, wintertime ozone variation below $35 \mathrm{~km}$ is rather complicated. Year-to-year variability of stratospheric polar ozone is mostly controlled by dynamical and chemical processes; both are essentially coupled to temperature changes. Factors that modify polar temperature, e.g., sudden strato- spheric warming (SSW) and El Niño-Southern Oscillation (ENSO), are essentially planetary wave perturbations that modulate the strength of polar vortex. The probabilities of major SSWs and, on the other hand, springs with extremely strong polar vortex are at similar levels as the one of SPEs. Thus, ozone variations by these events will be seen as robust signatures in our study as well, yet they do not necessarily coincide with onsets of SPEs with proton fluxes $>400 \mathrm{pfu}$ and $>10000$ pfu, respectively. The large SPE in January 2012 (Figs. 3 and 4) is severe enough to destroy stratospheric ozone. However, the stratospheric ozone anomalies at that time were dominated by dynamical ozone enhancement from SSW in 17 January 2012 (Päivärinta et al., 2016). One of the most pronounced examples of extreme strong polar vortex impact is the well-reported ozone depletion during spring of 2011, which can be observed in ozone anomalies around the two small SPEs that occurred in March 2011 (see Fig. A2). The lower-stratospheric polar vortex was the strongest (in either hemisphere) in the previous 32 years (Manney et al., 2011). A large volume of polar stratospheric clouds (PSCs) converted chlorine reservoirs to ozone-destroying species, leading to extraordinary low ozone levels in the stratosphere (Pommereau et al., 2018). Similarly, robust anomaly seen after January 2016 SPE can be explained by cold 2015-2016 winter anomaly. We are confident to exclude SPE's influence on the anomaly in both cases because (firstly) the signal is not following SPE onset and (secondly) these SPEs are such small events that ozone loss was not observed - not even in the mesosphere. These robust non-SPE signals are included in the superposed epoch analysis performed in Sect. 3, contributing to the robust anomalies below $30 \mathrm{~km}$ in Fig. 2 .

Identifying sources of the robust ozone anomaly below $35 \mathrm{~km}$ following the SPE beginning on 16 January 2005 is difficult. With a moderate cold winter temperature causing more ozone loss, coincident anomalies of robust dynamical ozone changes following the SPE exist. Meanwhile, an extremely large (over $270 \%$ ) ground-level enhancement (GLE) of neutrons occurred during the SPE period on 20 January 2005 (Jackman et al., 2011). Ionization rate reached $500 \mathrm{~cm}^{-3} \mathrm{~s}^{-1}$ at $30 \mathrm{~km}$ for $1 \mathrm{~d}$ due to the very high energy protons (300-20000 MeV) that caused the GLE (Usoskin et al., 2011). Jackman et al. (2011) carried out a detailed study of January 2005 SPE's influence on the northern polar atmosphere using WACCM3 simulation, and they reported an ozone column decrease of less than $0.01 \%$ by GLE protons, while the ozone changes below $50 \mathrm{~km}$ observed in MLS data were attributed to seasonal changes. The MLS ozone anomalies we observe are, on the contrary to the analysis in Jackman et al. (2011), not due to seasonal changes. To identify whether the anomalies are due to direct SPE effect or not, relative ozone response from MLS and WACCM-D simulation in MLS observation time and location to 16 January 2005 SPE are compared in Fig. 5. As WACCM-D simulations are carried out in the specified dynamics mode, any dynamical variations of ozone, including ozone chemistry, are expected 

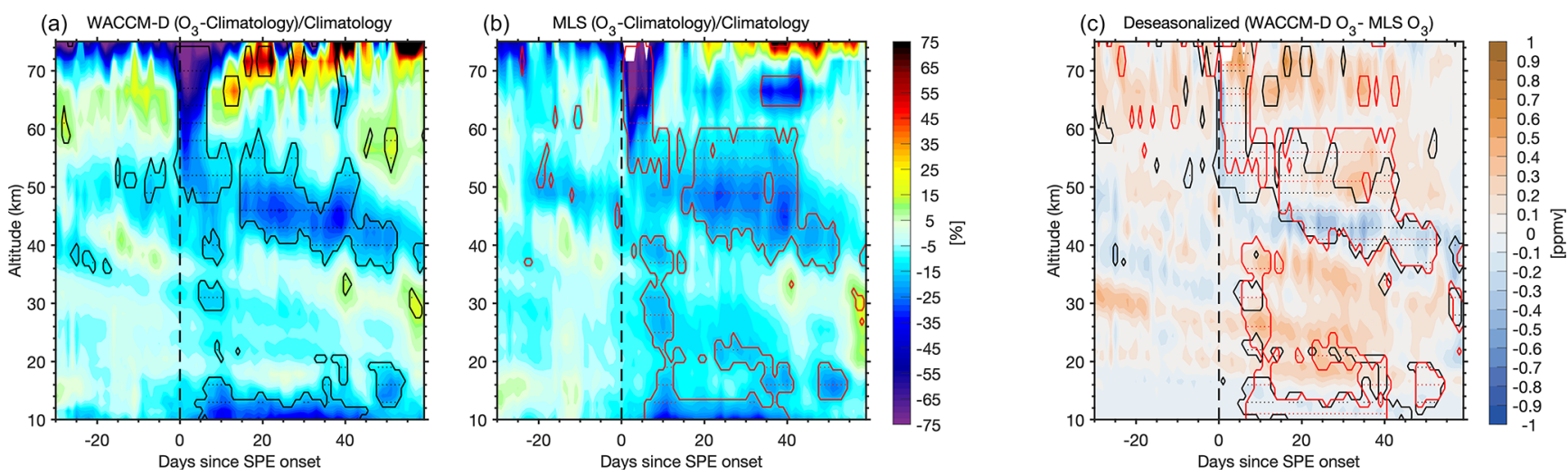

Figure 5. WACCM-D (a) and MLS (b) relative ozone anomalies along with altitude at $30 \mathrm{~d}$ before and $60 \mathrm{~d}$ after SPE on 16 January 2005. The WACCM-D simulations used here are the profiles at MLS measurement time and locations. The climatology was calculated using data between July 2004 and December 2012 for both MLS and WACCM-D. The black and red thick line area demonstrates the relative ozone anomalies with $>95 \%$ confidence after the Monte Carlo test. Panel (c) shows ozone differences between WACCM-D and MLS during this time frame (deseasonalized means that the seasonal differences shown in Fig. S4 were removed). The black and red thick line area demonstrates direct ozone anomalies with $>95 \%$ confidence after the Monte Carlo test from WACCM-D and MLS data, respectively.

to be reproduced by the model well. But any direct proton impacts below $25 \mathrm{~km}$ would not be reproduced at all since protons with energies $>300 \mathrm{MeV}$ are not included in the model input. So significant differences between the model and MLS response might indicate a direct proton impact. As shown in Fig. 5, ozone responses below $20 \mathrm{~km}$ are very similar between results derived from these two data sources $(5 \mathrm{~d}$ after SPE onset, close to the GLE event), indicating no significant proton effect. We do see some differences between 20 and $30 \mathrm{~km}$, which might demonstrate a possible direct proton effect. However, we would like to point out that compared to MLS, WACCM-D holds a $>20 \%$ overestimation of northern polar cap ozone below $30 \mathrm{~km}$ in January-April (see right panel of Figs. 5, S4 in the Supplement and Fig. 1 in Froidevaux et al., 2019). Such differences may implicate a transport-related issue in the model (Froidevaux et al., 2019) and therefore weaken our confidence to confirm the robust signal difference between MLS and WACCM-D at 20-30 km as the evidence of direct SPE impact. Readers who are interested in the ionization rate of this case are referred to Fig. A4.

Nonetheless, in our study the robust MLS ozone destruction signature in the lower stratosphere following the January 2005 SPE is unique not only when compared to other SPEs cases after 2004 but also when large and extreme SPEs before 2004 are included (see the WACCM-D simulation result presented in Fig. 6). Further research needs to be done to confirm the dynamical and chemical factors that led to ozone destruction below $35 \mathrm{~km}$ in January 2005 .

\section{Conclusions}

Recent studies have reported observations of up to $10 \%$ average decrease of lower-stratospheric ozone at $20 \mathrm{~km}$ altitude following solar proton events (SPEs). However, mechanisms which could cause such a large low-altitude impact are not clear. We used the Aura MLS satellite ozone datasets from 2004 to date and WACCM-D model simulations from 1989 to 2012 to analyze SPE-driven ozone changes. In our approach, stratospheric and mesospheric daily ozone anomalies $(10-70 \mathrm{~km})$ were examined over the epochs of SPEs by applying (1) a superposed epoch analysis (SEA) for all the cases and (2) a case-by-case analysis for individual events. Statistical significance of the anomalies found in the ozone levels was estimated by employing a Monte Carlo approach.

Arctic polar ozone destruction in the mesosphere and upper stratosphere can be directly observed from satellite measurement anomaly, when following SPEs in SeptemberApril with proton fluxes $>400 \mathrm{pfu}$ and $>1000 \mathrm{pfu}$, respectively. We observe 5\%-10\% ozone destruction below $30 \mathrm{~km}$ altitude in MLS SEA results. However, the depletion appears before the epoch time, i.e., SPE onset. We argue that such lower-stratospheric ozone losses are rather caused by an unusually stable and strong polar vortex, together with sufficient ozone-depleting reservoirs of chlorine as confirmed by the case-by-case study. In the case-by-case study, we find a very good overall consistency between SPE-driven ozone anomalies derived from the WACCM-D model simulations and the Aura MLS data. Despite the fact that the model can only detect direct proton effects above $25 \mathrm{~km}$ due to the input proton energy threshold of $300 \mathrm{MeV}$, the good consistency enables us to generalize the study also to the SPEs before the Aura MLS era. From 1989 to date, robust lowerstratospheric ozone decrease after SPEs was observed only once in ozone anomaly, i.e., following the January 2005 SPE. Ozone was depleted by $\sim 1 \mathrm{ppmv}(\sim 15 \%)$ at $20-35 \mathrm{~km}$ and by $\sim 0.15$ ppmv ( $>20 \%$ ) below $15 \mathrm{~km} 5 \mathrm{~d}$ after SPE onset. We further investigated this case by comparing WACCM-D and MLS data. Since WACCM-D is not expected to observe 

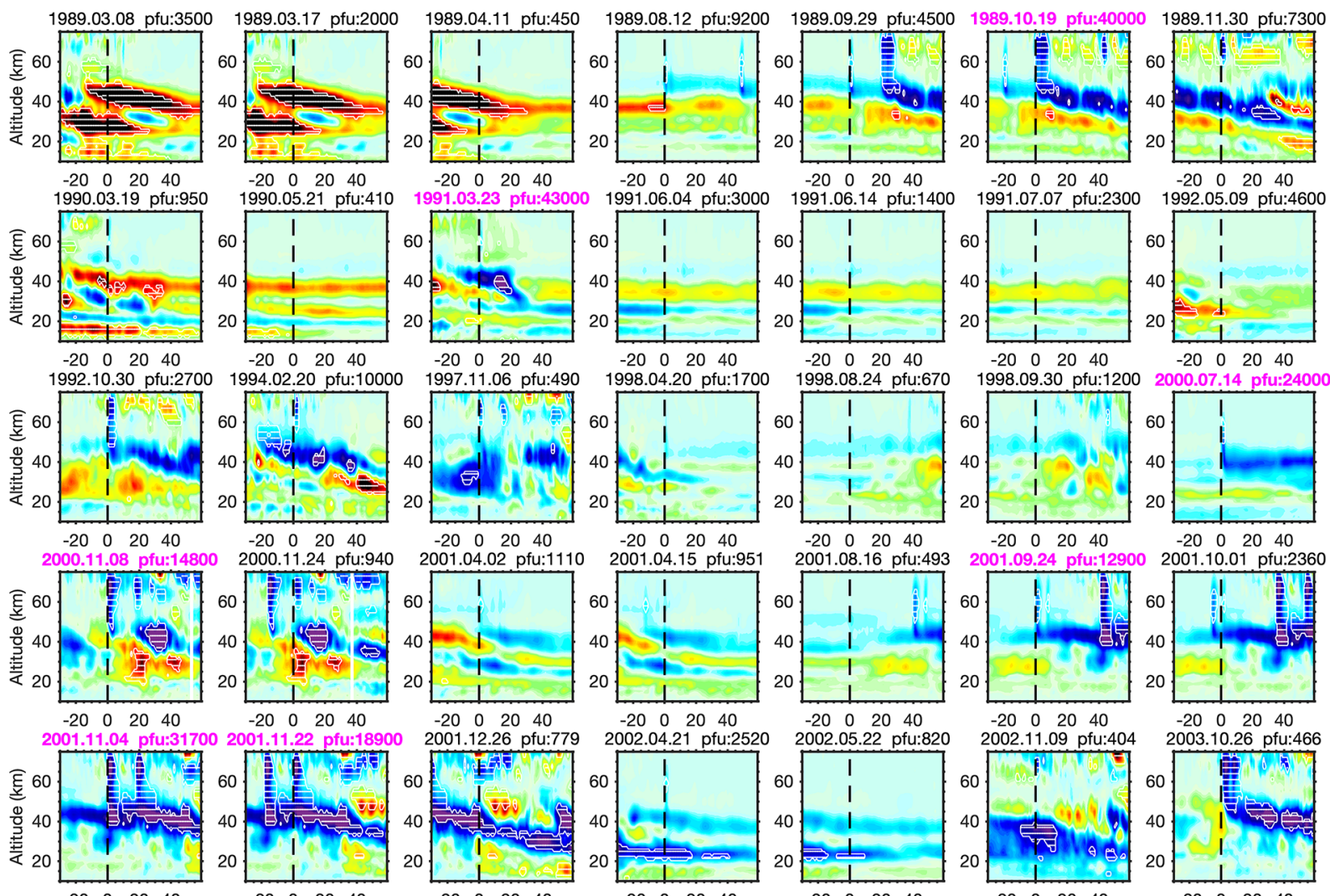

$\begin{array}{llll}-20 & 0 & 20 & 40\end{array}$

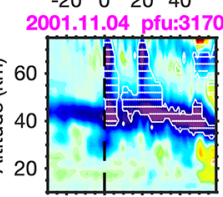

$-20 \quad 0 \quad 20 \quad 40$

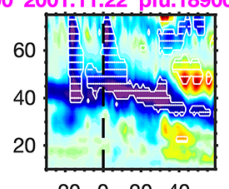

$\begin{array}{llll}-20 & 0 & 20 & 40 \\ 2003.10 .28 & \text { pfu: } 29500\end{array}$
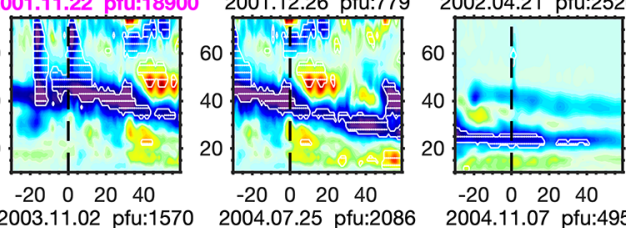

$-20 \quad 0 \quad 20 \quad 40$
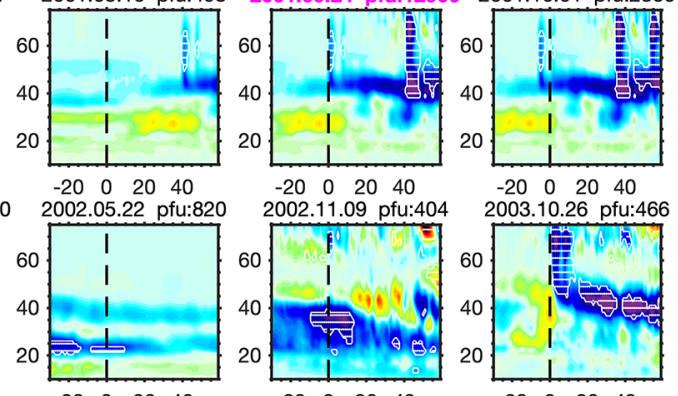

$\begin{array}{llll}-20 & 0 & 20 & 40\end{array}$
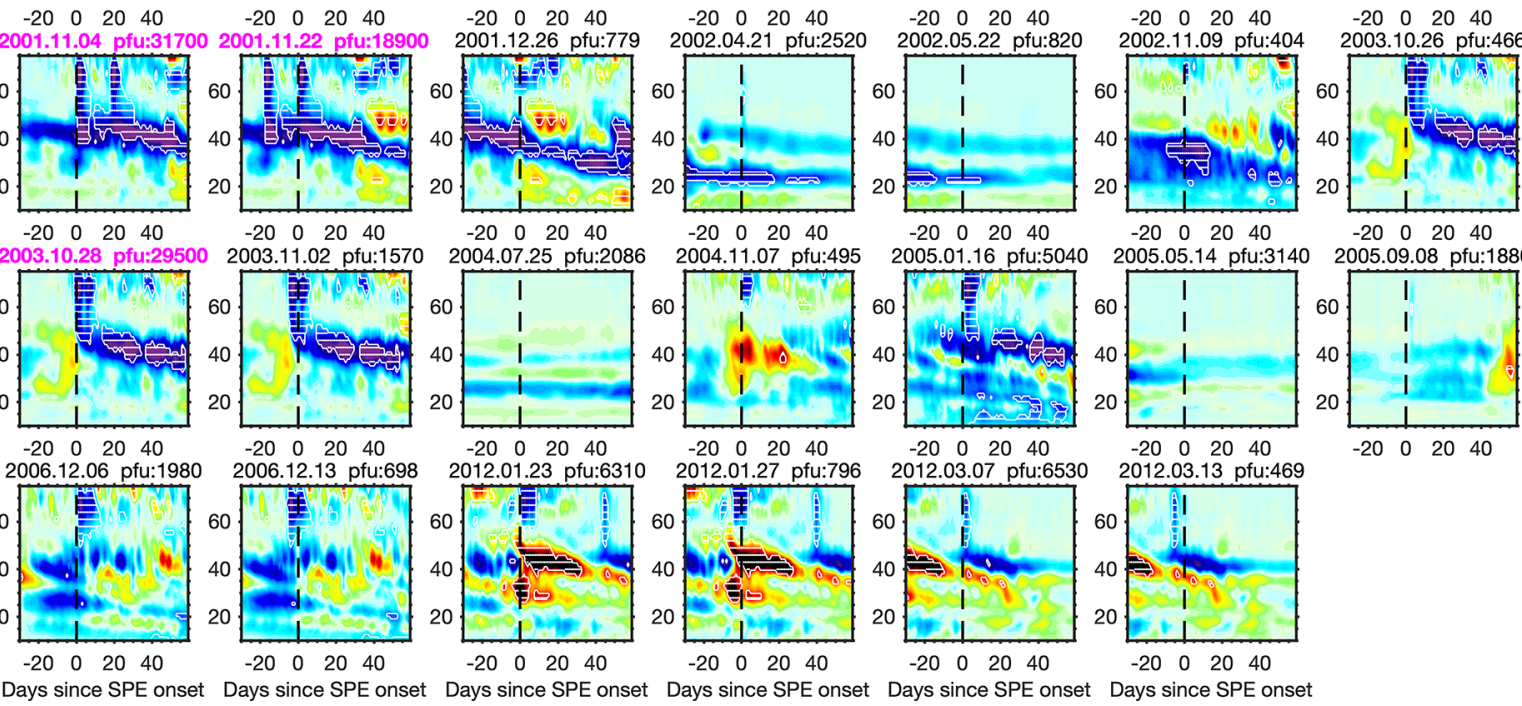

$-20 \quad 0 \quad 2040$

Days since SPE on

Figure 6. Same as Fig. 4 but for all simulated WACCM-D ozone anomalies (not only co-located with MLS measurement) before and after individual large SPEs (proton fluxes $>400 \mathrm{pfu}$ ) since 1989. Extreme SPEs (proton fluxes $>10000 \mathrm{pfu}$ ) are marked with bold magenta titles.

direct SPE impact below $25 \mathrm{~km}$, a consistent ozone depletion below $15 \mathrm{~km}$ demonstrated that direct SPE impact is less likely to be the reason for this robust ozone loss. The source of ozone loss above $20 \mathrm{~km}$, however, is not fully confirmed. We stress that the January 2005 event was followed by a GLE, but the SPE was not the strongest on record by far. The exact mechanisms of the suggested lower stratosphere impact following this event are currently unclear. The simulation results indicate that even for the strongest SPEs in our record, there is no significant effect on the lower-stratospheric ozone as such.
Although it remains unclear to what degree the lower ozone decrease in January 2005 was caused by the SPE, and how much was due to other natural variability, we suspect that the observed statistically significant lower-stratospheric ozone impact is most likely by chance coincident with the SPE onset. We note that further research on the January 2005 SPE case is necessary to solidly confirm the EPP dynamical and chemical factors that led to ozone destruction below $35 \mathrm{~km}$, but this is outside the scope of this paper. 


\section{Appendix A:}
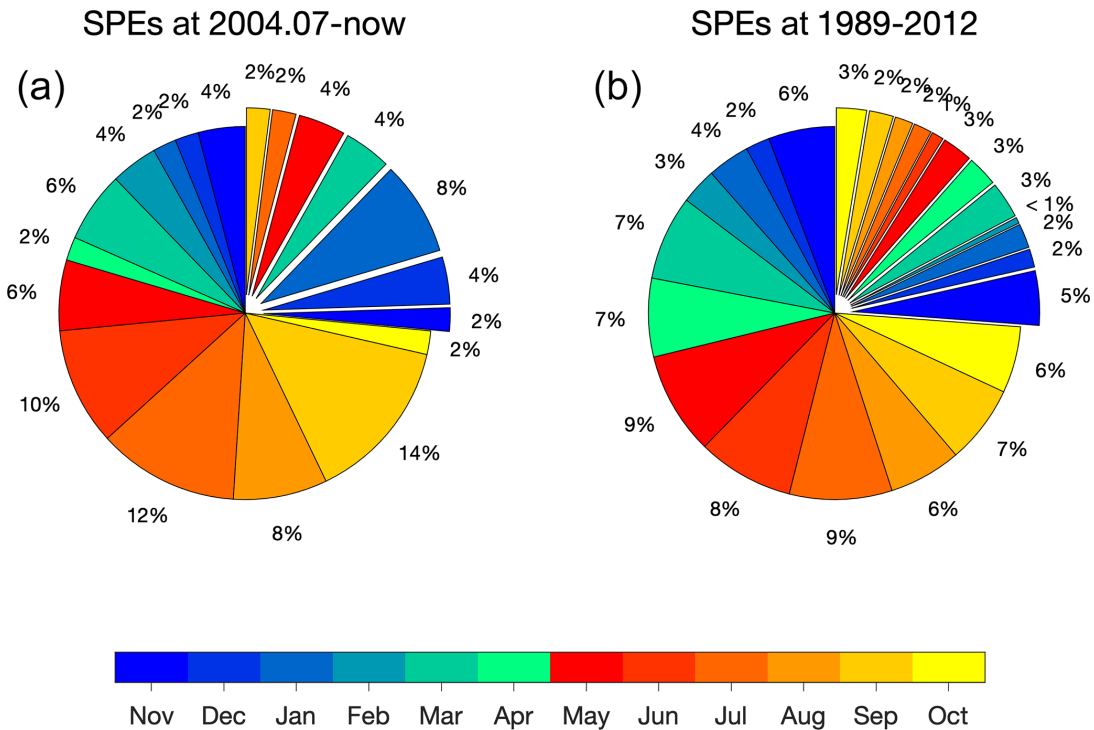

Figure A1. SPE seasonal distributions for those with fluxes $>400 \mathrm{pfu}$ (exploded parts of the pie charts) and the ones with fluxes $<400$ pfu (regular parts of the pie charts). Panel (a) demonstrates the cases in between the MLS measurement period (July 2004 to now). Panel (b) shows the cases during the WACCM-D simulation (1989-2012).
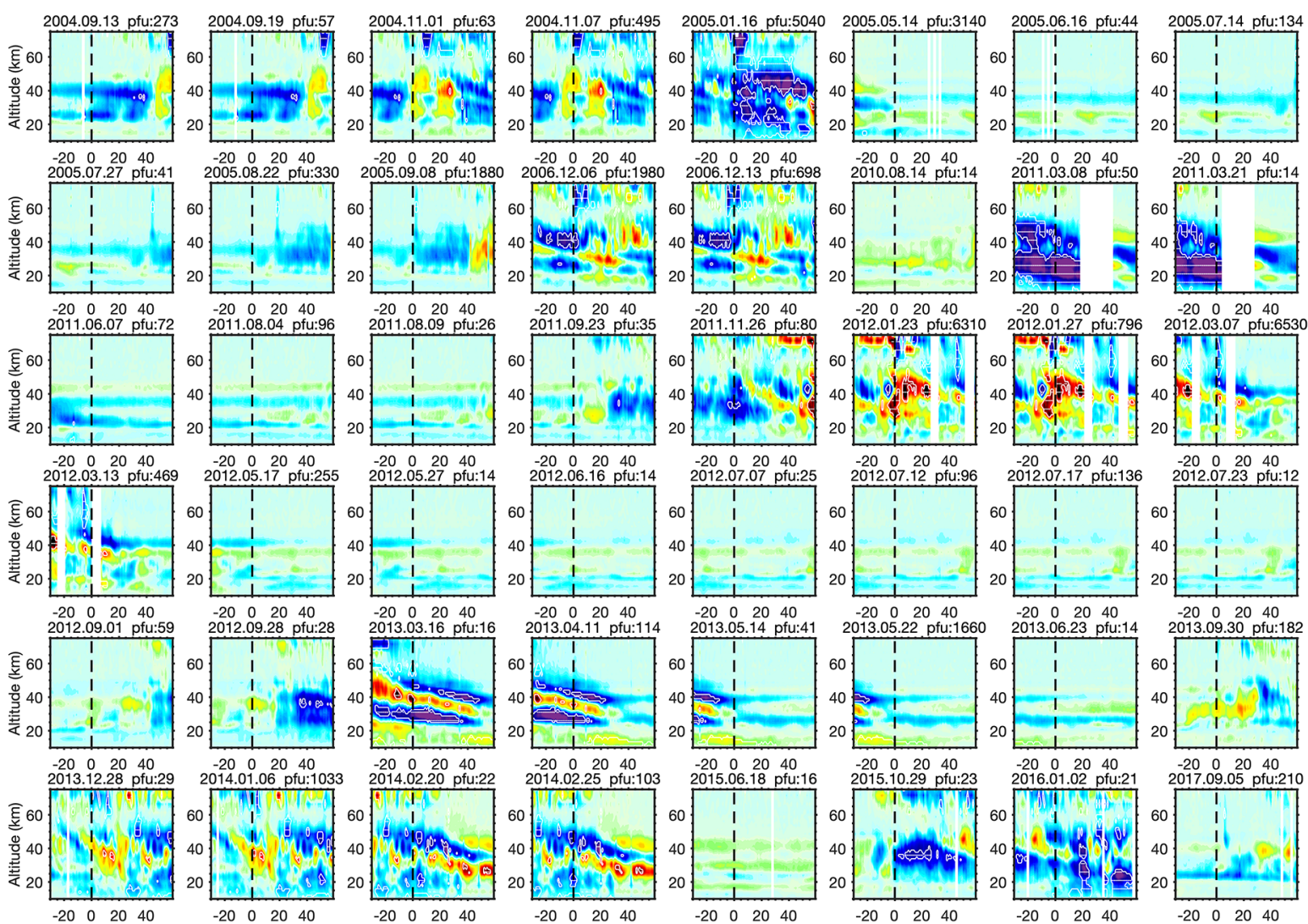

$-20 \quad 0 \quad 20 \quad 40$

$-20 \quad 0 \quad 20 \quad 40$
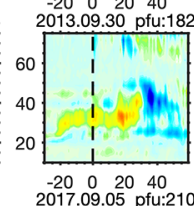

Figure A2. Same as Fig. 3 but after all individual SPEs since July 2004. 


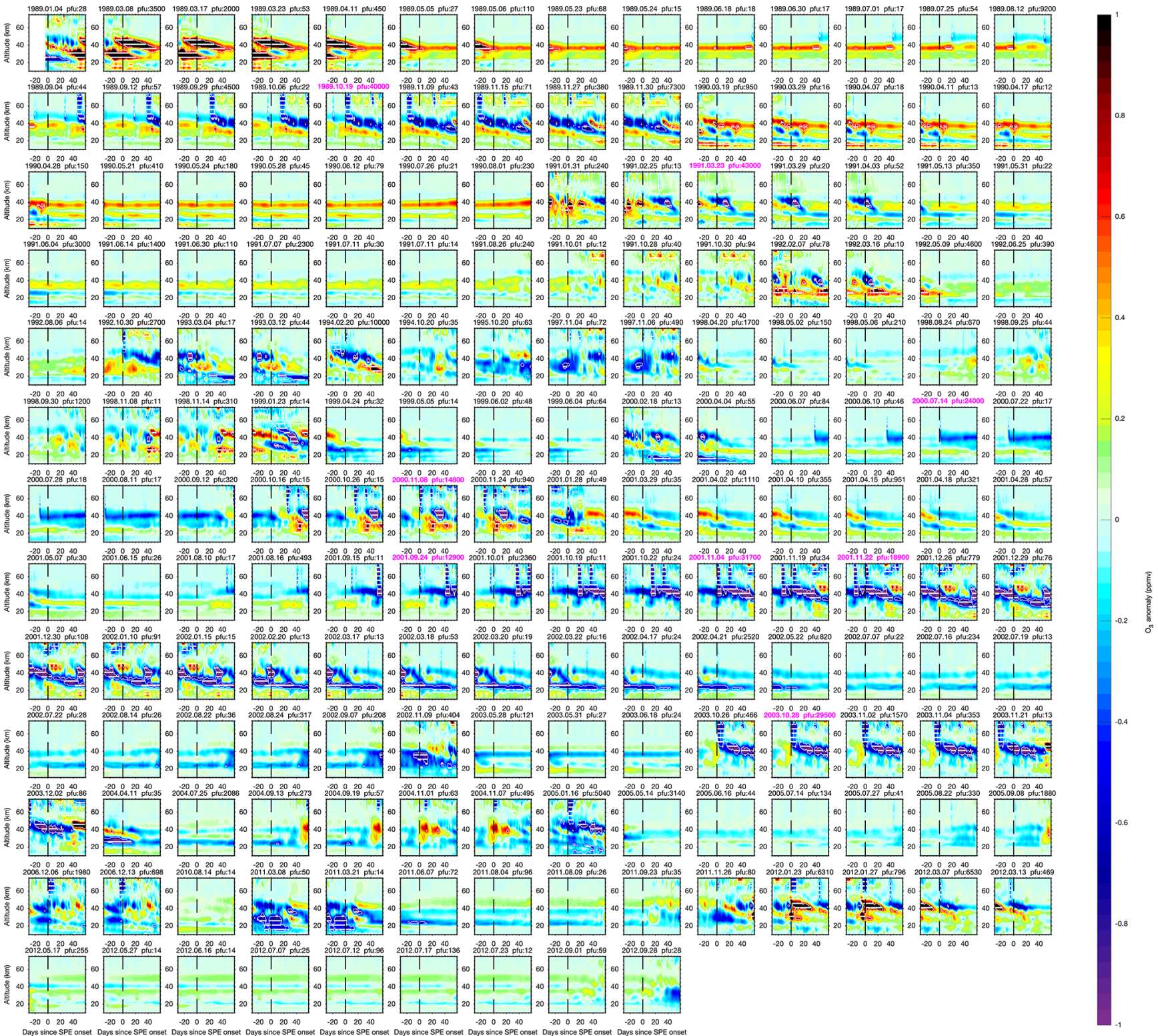

Figure A3. Same as Fig. 4 but after all individual SPEs since 1989. 


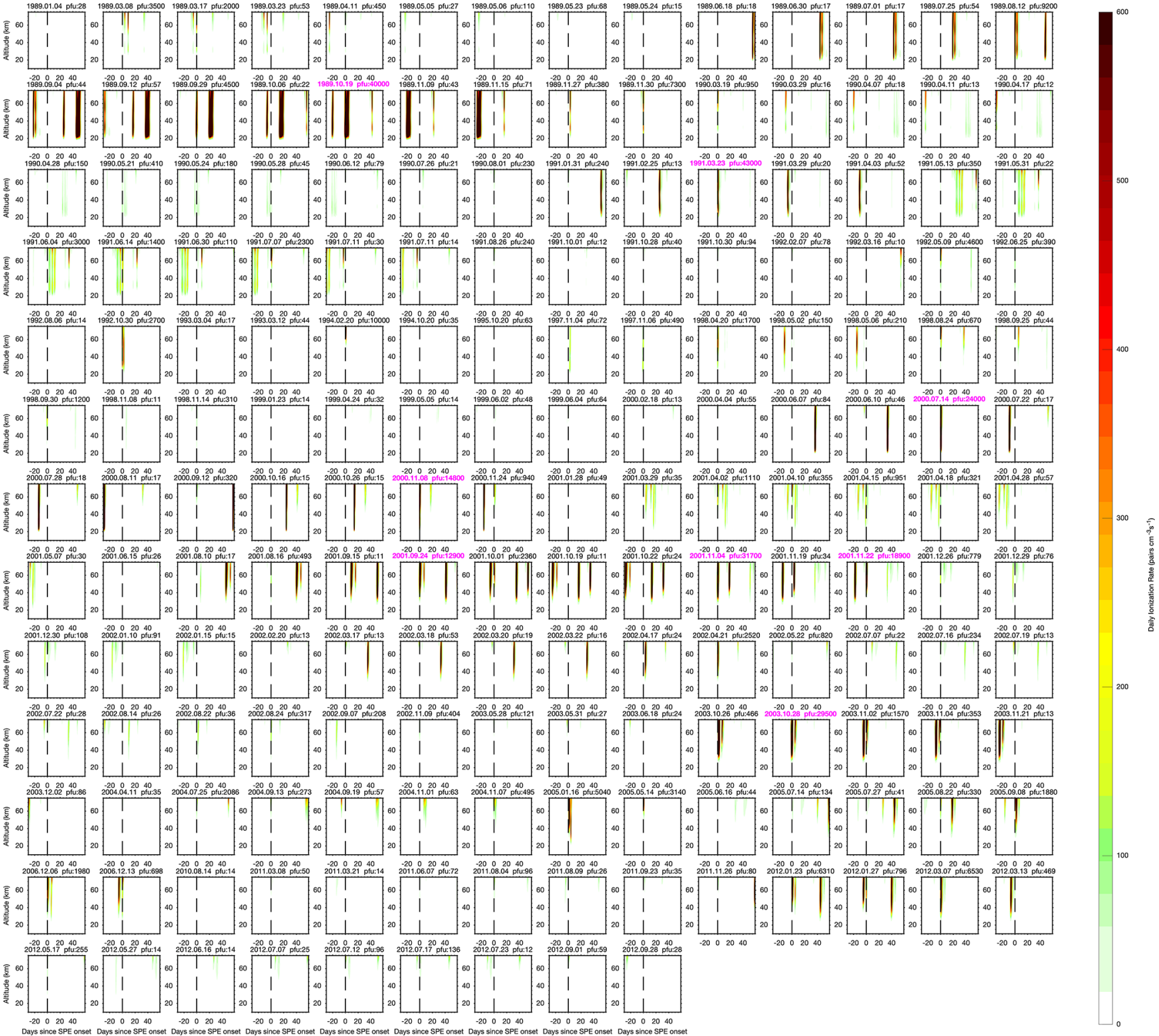

Figure A4. Daily averaged ionization rate along with altitude at $30 \mathrm{~d}$ before and $60 \mathrm{~d}$ after individual SPEs since 1989. 
Data availability. MLS ozone data used in this study are available at https://mls.jpl.nasa.gov/products/o3_product.php (last access: 19 November 2020, Livesey et al., 2018). Proton fluxes and solar proton events are available from https://www.ngdc.noaa.gov/stp/ satellite/goes/index.html (last access: 19 November 2020, NOAA, 2019). Daily geomagnetic activity Ap-index used in Fig. 1 can be found at https://www.ngdc.noaa.gov/stp/GEOMAG/kp_ap.html (last access: 19 November 2020, NOAA, 2019). The SPE-induced ionization rate dataset is available at https://solarisheppa.geomar.de/ solarprotonfluxes (last access: 19 November 2020, Jackman, 2011).

Supplement. The supplement related to this article is available online at: https://doi.org/10.5194/acp-20-14969-2020-supplement.

Author contributions. JJ and AK formed the idea of the work. JJ performed the analysis and wrote the paper with contributions from NK, PTV and AK. MES provided the WACCM-D model data. All the authors had intensive discussions about the method and results during the research.

Competing interests. The authors declare that they have no conflict of interest.

Acknowledgements. The work of Antti Kero is funded by the Tenure Track Project in Radio Science at Sodankylä Geophysical Observatory/University of Oulu. We would like to thank the MLS ozone teams for providing the ozone data. This work was carried out as a part of the International Space Science Institute (ISSI) project "Space Weather Induced Direct Ionisation Effects On The Ozone Layer". We appreciate the fruitful discussion with the group members in this project. We would like to thank the editor and the two anonymous referees for dedicating their time to this work.

Financial support. This research has been supported by the Kvantum Institute for the Mesospheric Monitoring of Ozone (MeMO) project.

Review statement. This paper was edited by Gabriele Stiller and reviewed by two anonymous referees.

\section{References}

Andersson, M. E., Verronen, P. T., Marsh, D. R., Päivärinta, S., and Plane, J. M. C.: WACCM-D-Improved modeling of nitric acid and active chlorine during energetic particle precipitation, J. Geophys. Res.-Atmos., 121, 10328-10341, https://doi.org/10.1002/2015JD024173, 2016.

Damiani, A., Funke, B., Loìpez Puertas, M., Santee, M. L., Cordero, R. R., and Watanabe, S.: Energetic particle precipitation: A major driver of the ozone budget in the Antarc- tic upper stratosphere, Geophys. Res. Lett., 43, 3554-3562, https://doi.org/10.1002/2016GL068279, 2016.

Denton, M. H., Kivi, R., Ulich, T., Rodger, C. J., Clilverd, M. A., Horne, R. B., and Kavanagh, A. J.: Solar proton events and stratospheric ozone depletion over northern Finland, J. Atmos. Sol.-Terr. Phy., 177, 218-227, https://doi.org/10.1016/j.jastp.2017.07.003, 2018a.

Denton, M. H., Kivi, R., Ulich, T., Clilverd, M. A., Rodger, C. J., and von der Gathen, P.: Northern hemisphere stratospheric ozone depletion caused by solar proton events: the role of the polar vortex, Geophys. Res. Lett., 45, 2115-2124, https://doi.org/10.1002/2017GL075966, 2018b.

Turunen, E., Verronen, P. T., Seppälä, A., Rodger., C. J., Mark Clilverd, M. A., Tamminen, J., Enell, C., and Ulich., T.: Impact of different energies of precipitating particles on $\mathrm{NO}_{x}$ generation in the middle and upper atmosphere during geomagnetic storms, J. Atmos. Sol.-Terr. Phy., 71, 1176-1189, https://doi.org/10.1016/j.jastp.2008.07.005, 2009.

Froidevaux, L., Kinnison, D. E., Wang, R., Anderson, J., and Fuller, R. A.: Evaluation of CESM1 (WACCM) free-running and specified dynamics atmospheric composition simulations using global multispecies satellite data records, Atmos. Chem. Phys., 19, 4783-4821, https://doi.org/10.5194/acp-19-4783-2019, 2019.

Funke, B., Baumgaertner, A., Calisto, M., Egorova, T., Jackman, C. H., Kieser, J., Krivolutsky, A., López-Puertas, M., Marsh, D. R., Reddmann, T., Rozanov, E., Salmi, S.-M., Sinnhuber, M., Stiller, G. P., Verronen, P. T., Versick, S., von Clarmann, T., Vyushkova, T. Y., Wieters, N., and Wissing, J. M.: Composition changes after the "Halloween" solar proton event: the High Energy Particle Precipitation in the Atmosphere (HEPPA) model versus MIPAS data intercomparison study, Atmos. Chem. Phys., 11, 90899139, https://doi.org/10.5194/acp-11-9089-2011, 2011.

Funke, B., Loìpez-Puertas, M., Stiller, G. P., and von Clarmann, T.: Mesospheric and stratospheric $\mathrm{NO}_{y}$ produced by energetic particle precipitation during 2002-2012, J. Geophys. Res.-Atmos., 119, 4429-4446, https://doi.org/10.1002/2013JD021404, 2014.

Jackman, C.: Solar Proton Fluxes, available at: https://solarisheppa. geomar.de/solarprotonfluxes (last access: 19 November 2020), 2011.

Jackman, C. H., McPeters, R. D., Labow, G. J., Fleming, E. L., Praderas, C. J., and Russell, J. M.: Northern hemisphere atmospheric effects due to the July 2000 Solar Proton Event, Geophys. Res. Lett., 28, 2883-2886, https://doi.org/10.1029/2001gl013221, 2001.

Jackman, C. H. and Fleming, E. L.: Stratospheric ozone variations caused by solar proton events between 1963 and 2005, in: Climate Variability and Extremes during the Past 100 years, Advances in Global Change Research, edited by: Brönnimann, S., Luterbacher, J., Ewen, T., Diaz, H., Stolarski, R., and Neu, U., Springer, Dordrecht, 333-345, https://doi.org/10.1007/9781-254020-6766-2_23, 2008.

Jackman, C. H., Marsh, D. R., Vitt, F. M., Garcia, R. R., Fleming, E. L., Labow, G. J., Randall, C. E., López-Puertas, M., Funke, B., von Clarmann, T., and Stiller, G. P.: Short- and medium-term atmospheric constituent effects of very large solar proton events, Atmos. Chem. Phys., 8, 765-785, https://doi.org/10.5194/acp-8765-2008, 2008.

Jackman, C. H., Marsh, D. R., Vitt, F. M., Roble, R. G., Randall, C. E., Bernath, P. F., Funke, B., López-Puertas, M., 
Versick, S., Stiller, G. P., Tylka, A. J., and Fleming, E. L.: Northern Hemisphere atmospheric influence of the solar proton events and ground level enhancement in January 2005, Atmos. Chem. Phys., 11, 6153-6166, https://doi.org/10.5194/acp11-6153-2011, 2011.

Jackman, C. H., Randall, C. E., Harvey, V. L., Wang, S., Fleming, E. L., López-Puertas, M., Funke, B., and Bernath, P. F.: Middle atmospheric changes caused by the January and March 2012 solar proton events, Atmos. Chem. Phys., 14, 1025-1038, https://doi.org/10.5194/acp-14-1025-2014, 2014.

Kalakoski, N., Verronen, P. T., Seppälä, A., Szeląg, M. E., Kero, A., and Marsh, D. R.: Statistical response of middle atmosphere composition to solar proton events in WACCM-D simulations: the importance of lower ionospheric chemistry, Atmos. Chem. Phys., 20, 8923-8938, https://doi.org/10.5194/acp20-8923-2020, 2020.

Livesey, N. J., Read, W. G., Froidevaux, L., Lambert, A., Manney, G. L., Pumphrey, H. C., Santee, M. L., Schwartz, M. J., Wang, S., Cofield, R. E., Cuddy, D. T., Fuller, R. A., Jarnot, R. F., Jiang, J. H., Knosp, B. W., Stek, P. C., Wagner, P. A., and Wu, D. L.: EOS MLS Version 4.2x Level 2 data quality and description document, Tech. Rep., Jet Propulsion Laboratory D-33509 Rev. D, available at: https://mls.jpl.nasa.gov/products/o3_product.php (last access: 19 November 2020), 2018.

Manney, G. L., Santee, M. L, Rex, M., Livesey, N. J., Pitts, M. C., Veefkind, P., Nash, E. R., Wohltmann, I., Lehmann, R., Froidevaux, L., Poole, L. R., Schoeberl, M. R., Haffner, D. P., Davies, J., Dorokhov, V., Gernandt, H., Johnson, B., Kivi, R., Kyrö, E., Larsen, N., Levelt, P. F., Makshtas, A., McElroy, C. T., Nakajima, H., Parrondo, M. C., Tarasick, D. W., von der Gathen, P., Walker, K. A., and Zinoviev, N. S.: Unprecedented Arctic ozone loss in 2011, Nature, 478, 469-475, https://doi.org/10.1038/nature10556, 2011.

Marsh, D. R., Garcia, R. R., Kinnison, D. E., Boville, B. A., Sassi, F., Solomon, S. C., and Matthes, K.: Modeling the whole atmosphere response to solar cycle changes in radiative and geomagnetic forcing, J. Geophys. Res.-Atmos., 112, D23306, https://doi.org/10.1029/2006JD008306, 2007.

Marsh, D. R., Mills, M., Kinnison, D., Lamarque, J.-F., Calvo, N., and Polvani, L.: Climate change from 1850 to 2005 simulated in CESM1(WACCM), J. Climate, 26, 7372-7391, https://doi.org/10.1175/JCLI-D-12-00558.1, 2013.

Matthes, K., Funke, B., Andersson, M. E., Barnard, L., Beer, J., Charbonneau, P., Clilverd, M. A., Dudok de Wit, T., Haberreiter, M., Hendry, A., Jackman, C. H., Kretzschmar, M., Kruschke, T., Kunze, M., Langematz, U., Marsh, D. R., Maycock, A. C., Misios, S., Rodger, C. J., Scaife, A. A., Seppälä, A., Shangguan, M., Sinnhuber, M., Tourpali, K., Usoskin, I., van de Kamp, M., Verronen, P. T., and Versick, S.: Solar forcing for CMIP6 (v3.2), Geosci. Model Dev., 10, 2247-2302, https://doi.org/10.5194/gmd-10-2247-2017, 2017.

NOAA: Space weather database, available at: https://www.ngdc. noaa.gov/stp/satellite/goes/index.html, last access: 19 November 2020.

Päivärinta, S., Verronen, P., Funke, B., Gardini, A., Seppälä, A., and Andersson, M.: Transport versus energetic particle precipitation: Northern polar stratospheric $\mathrm{NO}_{x}$ and ozone in January-March 2012, J. Geophys. Res.-Atmos., 121, 60856100, https://doi.org/10.1002/2015JD024217, 2016.
Pommereau, J. P., Goutail, F., Pazmino, A., Lefevre, F., Chipperfield, M. P., Feng, W. H., Van Roozendael, M., Jepsen, N., Hansen, G., Kivi, R., Bognar, K., Strong, K., Walker, K., Kuzmichev, A., Khattatov, S., and Sitnikova, V.: Recent Arctic ozone depletion: Is there an impact of climate change? Comptes Rendus Geoscience, 350, 347-353, https://doi.org/10.1016/j.crte.2018.07.009, 2018.

Randall, C. E., Harvey, V. L., Singleton, C. S., Bailey, S. M., Bernath, P. F., Codrescu, M., Nakajima, H., and Russell, J. M.: Energetic particle precipitation effects on the Southern Hemisphere stratosphere in 1992-2005, J. Geophys. Res., 112, D08308, https://doi.org/10.1029/2006JD007696, 2007.

Rienecker, M. M., Suarez, M. J., Gelaro, R., Todling, R., Bacmeister, J., Liu, E., Bosilovich, M. G., Schubert, S. D., Takacs, L., Kim, G.-K., Bloom, S., Chen, J., Collins, D., Conaty, A., da Silva, A., Gu, W., Joiner, J., Koster, R. D., Lucchesi, R., Molod, A., Owens, T., Pawson, S., Pegion, P., Redder, C. R., Reichle, R., Robertson, F. R., Ruddick, A. G., Sienkiewicz, M., and Woollen, J.: MERRA - NASA's Modern-Era Retrospective Analysis for Research and Applications, J. Climate, 24, 3624 3648, https://doi.org/10.1175/JCLI-D-11-00015.1, 2011.

Seppälä, A., Verronen, P. T., Kyrölä, E., Hassinen, S., Backman, L., Hauchecorne, A., Bertaux, J. L., and Fussen, D.: Solar proton events of October-November 2003: Ozone depletion in the Northern Hemisphere polar winter as seen by GOMOS/Envisat, Geophys. Res. Lett., 31, L19107, https://doi.org/10.1029/2004GL021042, 2004.

Sinnhuber, M., Nieder, H., and Wieters, N.: Energetic Particle Precipitation and the Chemistry of the Mesosphere/Lower Thermosphere. Surv. Geophys., 33, 1281-1334, https://doi.org/10.1007/s10712-012-9201-3, 2012.

Stone, K. A., Solomon, S., and Kinnison, D. E.: On the Identification of Ozone Recovery, Geophys. Res. Lett., 45, 5158-5165, https://doi.org/10.1029/2018GL077955, 2018.

Usoskin, I. G., Kovaltsov, G. A., Mironova, I. A., Tylka, A. J., and Dietrich, W. F.: Ionization effect of solar particle GLE events in low and middle atmosphere, Atmos. Chem. Phys., 11, 19791988, https://doi.org/10.5194/acp-11-1979-2011, 2011.

Verronen, P. T., Seppälä, A., Kyrölä, E., Tamminen, J., Pickett, H. M., and Turunen, E.: Production of odd hydrogen in the mesosphere during the January 2005 solar proton event, Geophys. Res. Lett., 33, L24811, https://doi.org/10.1029/2006GL028115, 2006.

Verronen, P. T. and Lehmann, R.: Analysis and parameterisation of ionic reactions affecting middle atmospheric $\mathrm{HO}_{x}$ and $\mathrm{NO}_{y}$ during solar proton events, Ann. Geophys., 31, 909-956, https://doi.org/10.5194/angeo-31-909-2013, 2013.

Verronen, P. T., Andersson, M. E., Marsh, D. R., Kovács, T., and Plane, J. M. C.: WACCM-D - Whole Atmosphere Community Climate Model with D-region ion chemistry, J. Adv. Model. Earth Sy., 8, 954-975, https://doi.org/10.1002/2015MS000592, 2016.

Waters, J. W., Froidevaux, L., Harwood, R. S., Jarnot, R. F., Pickett, H. M., Read, W. G., Siegel, P. H., Cofield, R. E., Filipiak, M. J., Flower, D. A., Holden, J. R., Lau, G. K. K., Livesey, N. J., Manney, G. L., Pumphrey, H. C., Santee, M. L., Wu, D. L., Cuddy, D. T., Lay, R. R., Loo, M. S., Perun, V. S., Schwartz, M. J., Stek, P. C., Thurstans, R. P., Boyles, M. A., Chandra, K. M., Chavez, M. C., Chen, G. S., Chudasama, B. V., Dodge, R., Fuller, R. A., Girard, M. A., Jiang, J. H., Jiang, Y. B., Knosp, B. 
W., LaBelle, R. C., Lam, J. C., Lee, K. A., Miller, D., Oswald, J. E., Patel, N. C., Pukala, D. M., Quintero, O., Scaff, D. M., Van Snyder, W., Tope, M. C., Wagner, P. A., and Walch, M. J.: The Earth Observing System Microwave Limb Sounder (EOS MLS) on the Aura satellite, IEEE T. Geosci. Remote, 44, 1075-1092, https://doi.org/10.1109/TGRS.2006.873771, 2006. 